\title{
Contribuições dos jogos matemáticos e modelagem Matemática no ensino da
}

\section{Matemática}

\author{
Contributions of Mathematical games and Mathematical modeling in teaching Mathematics \\ Contribuciones de los juegos matemáticos y el modelado matemático em la enseñanza de las \\ Matemáticas
}

Recebido: 17/12/2021 | Revisado: 26/12/2021 | Aceito: 07/01/2022 | Publicado: 10/01/2022

\author{
Alana Cavalcante Felippe \\ ORCID: https://orcid.org/0000-0001-8106-963X \\ Universidade Federal de Viçosa, Brasil \\ E-mail: alana@ufv.br \\ Shirley da Silva Macedo \\ ORCID: https://orcid.org/0000-0002-0171-6532 \\ Universidade Federal de Catalão, Brasil \\ E-mail: sdasilvamacedo@gmail.com
}

\begin{abstract}
Resumo
Este trabalho é uma compilação de alguns textos sobre a importância da modelagem matemática e jogos matemáticos no ensino e aprendizagem de conteúdos da educação básica. Tem por objetivo analisar a influência positiva de jogos matemáticos e modelagem matemática como ferramentas de ensino. Para tanto, realizamos uma análise das políticas públicas orientadoras de currículos e de trabalhos já publicados, pautados na exposição dos jogos matemáticos como estratégias de ensino, bem como na modelagem matemática sendo uma das possibilidades metodológicas com capacidade de trazer novas contribuições para o ensino efetivo contextualizado. Destacamos alguns dos desafios no processo educativo e a interferência que os jogos matemáticos e a modelagem matemática exercem neste processo. Nas metodologias mencionadas, é possível perceber que um professor pode ensinar levando em consideração a realidade dos alunos. Identificamos, a partir da leitura e análise dos documentos estudados, a importância da conexão entre a escola e a Matemática com o intuito de preparar os alunos para a sociedade em que estão inseridos, contribuindo para a formação de cidadãos com responsabilidade, capazes de participar ativamente no mundo permeado pela ciência e tecnologia.
\end{abstract}

Palavras-chave: Jogos matemáticos; Modelagem matemática; Ensino; Aprendizagem.

\begin{abstract}
This work is a compilation of some texts about how important mathematics modeling and mathematical games at teaching and learning these contents at elementary school. The goal is to analyse the positive influence of mathematical games and mathematical modeling like teaching tools. Therefore, we made a public policy analysis curriculum guide and of works already published, based on the exhibition of mathematical games as teaching strategies, as well as mathematical modeling being one of the methodological possibilities with the capacity of bringing down new contributions to the contextualized and effective teaching. We highligh some challenges at the educational process and the interference that mathematical games and mathemaical modeling exercise in this process. In these methodologies quoted, it's possible to realize that a teacher can teach taking into account the reality of the students. We identify from reading and analysis of the studied documents how important is the conecction between school and Mathematics with the intent to prepare students for the society in which they live, contributing to the formation of responsible citizens being able to participate actively in the world permeated by science and technology. Keywords: Mathematical games; Mathematical modeling; Teaching; Learning.
\end{abstract}

\section{Resumen}

Este trabajo es una recopilación de algunos textos sobre la importancia del modelado matemática y los juegos matemáticos en la enseñanza y el aprendizaje de contenidos de educación básica. Tiene como objetivo analizar la influencia positiva de los juegos matemáticos y el modelado matemático como herramientas de enseñanza. Por lo tanto, realizamos un análisis de las políticas públicas que orientan los planes de estudio y de trabajos publicados, basados en la exposición de los juegos matemáticos como estrategias de enseñanza, así como en modelado matemático como una de las posibilidades metodológicas capaces de aportar nuevos aportes a la enseñanza contextualizada efectiva. Destacamos algunos de los desafíos en el proceso educativo y la interferencia que los juegos matemáticos y el modelado matemático ejercen en este proceso. En las metodologías mencionadas, es posible ver que un docente puede enseñar teniendo en cuenta la realidad de los estudiantes. Identificamos, a partir de la lectura y 
análisis de los documentos estudiados, la importancia de la conexión entre la escuela y la Matemática con el fin de preparar a los estudiantes para la sociedad en la que viven, contribuyendo a la formación de ciudadanos responsables, capaces de participar activamente en el mundo. impregnado de ciencia y tecnología.

Palabras clave: Juegos matemáticos; Modelado matemático; Enseñanza; Aprendizaje.

\section{Introdução}

Ensinar Matemática é uma atividade que exige uma constante reflexão por parte do professor pois exige uma busca contínua de novas metodologias que possam contribuir de forma significativa na formação matemática dos alunos. A busca por novas metodologias se dá a partir das dificuldades apresentadas no ensino e aprendizagem dos conteúdos matemáticos. Um dos desafios que o processo educativo apresenta é a deficiência de aprendizagem por parte de vários alunos. As metodologias de ensino tradicionais, alicerçadas em memorização de regras e fórmulas, tornam o aprendizado dos conteúdos desinteressantes e sem sentido para o aluno, desde que não estejam vinculados à realidade.

“[...] ensinar não é transmitir conhecimento, mas criar possibilidades para sua produção ou a sua construção... não há docência sem discência, as duas se explicam e seus sujeitos, apesar das diferenças que as conotam, não se reduzem à condição de objeto, um do outro. Quem ensina aprende ao ensinar e quem aprende ensina ao aprender. Quem ensina, ensina alguma coisa a alguém [...] (Freire, 1998, p.25)."

De acordo com Libâneo (2010), a educação ocorre em diferentes espaços frequentados pelos cidadãos, ressaltando que a escola não é o único lugar de absorção de conhecimento. Apesar disso, a escola é um lugar propício para consolidar a construção do conhecimento, pois, dentre outros fatores, a presença ativa dos professores é indispensável para que haja interação entre professor-aluno. A interferência do professor quanto à apresentação de conteúdos, colabora significativamente para que a forma de aprender se torne interessante e com sentido para o aluno.

Apesar da Matemática ser uma ciência hipotética-dedutiva, é notório considerar seu papel experimental, em particular em situações simples do cotidiano. Alternativas que podem propiciar uma aprendizagem sólida são aquelas que trazem o aluno para situações reais, como calcular compras no supermercado, contar o tempo no relógio, na música, preparar uma receita ou administrar o dinheiro que recebe dos pais ou responsáveis. Esta ideia está alinhada à Base Nacional Comum Curricular BNCC (2017) que defende a aplicação dos conhecimentos da vida real, priorizando o contexto para dar sentido ao que se aprende e destacando o aluno como protagonista do seu aprendizado.

Este trabalho é uma compilação de alguns textos sobre a importância da modelagem matemática e jogos matemáticos no ensino e aprendizagem de conteúdos da educação básica. Tem por objetivo analisar a influência positiva de jogos matemáticos e modelagem matemática como ferramentas de ensino e aprendizagem em conteúdos da educação básica. Evidenciamos os benefícios de utilizar jogos matemáticos e modelagem matemática como recursos metodológicos para um ensino efetivo.

Para tal, realizamos leituras de autores envolvidos com a modelagem matemática, com contribuições significativas para a pesquisa e o ensino de Matemática, dentre eles D’Ambrosio (1986, 2009), Bassanezi (2002) e Biembengut (1999, 2005). Além de estudiosos da Educação Matemática como Grando (2004), Agranionih e Smaniotto (2002) e Smole et al (2007) que apresentam suas opiniões favoráveis acerca dos jogos matemáticos se tornarem estratégias notáveis na construção de conceitos matemáticos, além de materiais relacionados às políticas públicas orientadoras de currículo.

Destacamos alguns dos desafios no processo educativo e a interferência que os jogos matemáticos e a modelagem matemática exercem nesse processo. Nas metodologias estudadas, é possível perceber que um professor pode ensinar levando em consideração as condições de seus alunos, visto que as mesmas funcionam como ferramentas relevantes na Matemática, 
pois estimula a curiosidade, criatividade e raciocínios estratégicos dos discentes na busca de meios viáveis para resolução das situações e alcance dos resultados almejados.

Nas metodologias supracitadas, observamos a capacidade que ambas possuem de trazer os conteúdos matemáticos mais próximos dos alunos promovendo uma dialética entre teoria e prática incentivando a formação de indivíduos pensantes, críticos e conscientes do seu papel no contexto social.

\section{Metodologia}

Em termos de procedimentos técnicos, este trabalho tem a característica de pesquisa bibliográfica. Com a finalidade de sintetizar resultados obtidos em pesquisas sobre a importância dos jogos matemáticos e da modelagem matemática no ensino, realizamos a revisão integrativa de literatura já publicada em forma de livros, artigos, dissertações e trabalhos apresentados em congressos.

A partir da identificação do tema, foram utilizados os seguintes critérios para a seleção de materiais bibliográficos: conhecimento sobre as diretrizes norteadoras da aprendizagem essencial que devem ser desenvolvidos por todos os estudantes no território nacional, a busca por teóricos renomados que trazem reflexões acerca da modelagem matemática e dos jogos matemáticos, a correlação existente entre os desafios do ensino da matemática e a utilização destas ferramentas como facilitadoras da aprendizagem.

Sendo assim, inicialmente realizamos um estudo das políticas públicas orientadoras de currículo, tais como os Parâmetros Curriculares Nacionais (PCN's) e Base Nacional Comum Curricular (BNCC), ambos disponíveis na internet. Posteriormente, nos apoiamos em alguns trabalhos já publicados pautados na exposição dos jogos matemáticos como estratégias de ensino, bem como na modelagem matemática sendo uma das possibilidades metodológicas com potencialidade de trazer novas contribuições para o ensino, promovendo aprendizagem baseada na realidade do aluno.

Realizamos leituras de alguns dos principais estudiosos da Modelagem Matemática, com contribuições significativas para a pesquisa e o ensino de Matemática, dentre eles D'Ambrosio (1986, 2009), Bassanezi (2002) e Biembengut (1999, 2005). Além disso, destacamos alguns autores que contribuíram com estudos acerca da importância dos jogos matemáticos, tais como Borin (1996), Agranionih e Smaniotto (2002), Grando (2004), Sarmento et al (2018), dentre outros.

As pesquisas analisadas buscaram desenvolver uma análise de como os conteúdos matemáticos ministrados em sala de aula pelos professores, podem ser vivenciados no dia a dia dos alunos através da utilização de jogos matemáticos e da Modelagem Matemática. Desta forma, estas ferramentas promovem uma dialética entre teoria e prática, incentivando a formação de indivíduos pensantes, críticos e conscientes do seu papel no contexto social.

\section{Fundamentação Teórica}

\subsection{Desafios no processo educativo}

Ensinar Matemática requer a constante atividade reflexiva do professor acerca dos meios viáveis para a construção do conhecimento discente, diante das dificuldades enfrentadas no processo educativo. Um dos desafios apresentados é a dificuldade de aprendizagem por parte de vários alunos.

Segundo Scoz (1996), os problemas de dificuldades de aprendizagem são multidimensionais, ou seja,

“[...] os problemas de aprendizagem não são restringíveis nem a causas físicas ou psicológicas, nem a análises das conjunturas sociais. É preciso compreendê-los a partir de um enfoque multidimensional, que amalgame fatores orgânicos, cognitivos, afetivos, sociais e pedagógicos, percebidos dentro das articulações sociais (Scoz, 1996, p. 22).” 
Sob o ponto de vista de Libâneo (1994), a aprendizagem é dividida em dois tipos: a aprendizagem casual, que traz a espontaneidade e a aprendizagem organizada com seu caráter sistemático. Mais precisamente,

"Existem dois tipos fundamentalmente diferentes de aprendizagem: a aprendizagem casual e a organizada. A aprendizagem casual é a aprendizagem espontânea, surge naturalmente da interação com outras pessoas, ou seja, do convívio social, pela observação de objetos e acontecimentos, pelo contato com as mídias, leituras e conversas informais etc. Já a aprendizagem organizada tem caráter intencional, sistemático, cuja finalidade peculiar é a construção do conhecimento (Libâneo, 1994, p. 82).”

Em um trabalho mais recente, Libâneo (2010) ressalta que a educação ocorre em diferentes espaços frequentados pelos cidadãos.

"Na casa, na rua, na igreja ou na escola, de um modo ou de muitos, todos nós envolvemos pedaços da vida com ela:
para aprender, para ensinar, para aprender-e-ensinar. Para saber, para fazer, para ser ou para conviver, todos os dias
misturamos a vida com a educação. Com uma ou com várias: educaçã̃o? Educações. (...) Não há uma forma única
nem um único modelo de educação; a escola não é o único lugar em que ela acontece e talvez nem seja o melhor; o
ensino escolar não é a única prática, e o professor profissional não é seu único praticante (Libâneo, 2010, p. 26)."

Embora a aprendizagem aconteça em diferentes lugares, como destaca Libâneo (2010), convém ressaltar que a escola é um lugar propício para consolidar a construção do conhecimento. Ela exerce uma importante contribuição no processo educativo, visto que é o local onde ocorre a interação professor-aluno.

Sob a perspectiva de D'Ambrósio (2009), o desafio para a educação está relacionado com o hoje e o amanhã.

"O grande desafio para a educação é pôr em prática hoje o que vai servir para o amanhã. Pôr em prática significa levar pressupostos teóricos, isto é, um saber/fazer acumulado ao longo de tempos passados, ao presente. Os efeitos da prática de hoje vão se manifestar no futuro. Se essa prática foi correta ou equivocada só será notado após o processo e servirá como subsídio para uma reflexão sobre os pressupostos teóricos que ajudarão a rever, reformular, aprisionar o saber/fazer que orienta nossa prática (D'Ambrósio, 2009, p. 80).”

Dauanny (1994) afirma que grande parte das dificuldades especiais no que refere ao conhecimento matemático decorre do fato de muitos verbalizarem que a Matemática é um lugar de abstrações.

"Grande parte das dificuldades especiais atribuídas ao conhecimento matemático decorre justamente do fato de a Matemática ser considerada o lugar das abstrações, é consequência disso. Entretanto, não são suas características intrínsecas que a empurram para o terreno das abstrações, mas sim as características, digamos, impostas, ou que acostumamos a associar-lhe (Dauanny, 1994, p.22).”

Nesse sentido, Unesco (2016) afirma que

"A atividade matemática é, de fato, uma atividade humana com múltiplas facetas, muito longe dos estereótipos atribuídos a ela na cultura popular. Uma educação matemática de qualidade deve, portanto, refletir essa diversidade por meio de diferentes conteúdos matemáticos que sejam apresentados progressivamente aos alunos: propor os problemas ou reformulá-los para torná-los acessíveis a um trabalho matemático, modelar, explorar, conjecturar, experimentar, representar e formular, desenvolvendo linguagens específicas, argumentar e provar, desenvolver métodos, elaborar os conceitos e relacioná-los dentro de espaços estruturados, trocar e comunicar... (Unesco, 2016, p.5)."

É oportuno destacar que em fatos simples do nosso cotidiano, o processo de aprendizagem ocorre a todo momento. Segundo Goulart (2002, p.77) “A aprendizagem está associada a todo o âmbito do desenvolvimento humano: aprende-se a comer certos pratos, aprende-se a ter vontades, interesses, a amar, odiar e temer adquirem-se traços de personalidade, aprendendo." 
Outro desafio enfrentado pelos educadores consiste nas salas de aula superlotadas e na diferença da realidade social de cada aluno, influenciando no seu desempenho escolar e/ou acadêmico. Segundo Vygotsky (2003, p.79), “[...] o processo educativo é trilateralmente ativo: o aluno, o professor e o meio existente entre eles são ativos."

A fim de que o conteúdo matemático tenha significado para o aluno, é preciso considerar as múltiplas realidades existentes na sala de aula. Nacarato $(2013$, p.20) levanta a seguinte questão: "Como é possível um professor ensinar matemática sem levar em consideração as condições de seus alunos? Muitos vêm para a escola, pois nela encontram alimentação, amigos, com quem conversar..."

O aprendizado ocorre quando o aluno consegue associar o conteúdo com suas experiências. Segundo Nacarato (2013), para a Matemática fazer sentido para os alunos, independentemente da sua origem socioeconômica, ela precisa ser vista como situações de resolução de problemas. O aluno deve ser o protagonista na construção do conhecimento matemático, formulando questões e tomando decisões.

Apesar da Matemática ser uma ciência hipotética-dedutiva, é notório considerar seu papel experimental. Uma das grandes problemáticas no método tradicional de ensino é a forma como o conteúdo é exposto e aplicado, priorizando a teoria de fato. As discussões em busca de metodologias inovadoras que tornem o ensino da matemática mais significativo, aproximando o aluno da realidade em que vive, têm sido frequentes.

Por outro lado, a presença e participação ativa dos professores nas aulas é imprescindível para que a relação professor-aluno se estabeleça. A busca por novos métodos de ensino que favoreçam a compreensão e a associação da Matemática com a realidade do aluno devem ser constantes por parte dos professores, favorecendo assim estes laços.

\subsection{Algumas ferramentas matemáticas no processo de ensino}

O uso da metodologia tradicional em detrimento a mínima disposição dos professores para utilização de novos recursos didáticos, pode gerar dificuldades no ensino e aprendizagem de matemática, levando a desmotivação pelo discente.

Uma alternativa viável para proporcionar uma aprendizagem sólida e significativa é trazer o aluno para situações do cotidiano, como calcular compras no supermercado, contar o tempo no relógio, na música, preparar uma receita, administrar o dinheiro que recebe dos pais ou responsáveis.

A Base Nacional Comum Curricular (BNCC) Brasil (2017) defende a aplicação dos conhecimentos na vida real, destacando a relevância do contexto, a fim de dar sentido ao conteúdo que o aluno está aprendendo. Desta maneira, evidencia o protagonismo do estudante no processo de ensino e aprendizagem.

A utilização de atividades realizadas com recursos lúdicos, como por exemplo, os jogos matemáticos em sala de aula, bem como a modelagem matemática mostram-se ferramentas relevantes no processo educativo. Na busca de meios viáveis para resolução das situações e alcance dos resultados almejados, estas ferramentas estimulam a curiosidade, criatividade e raciocínios estratégicos nos discentes.

As metodologias mencionadas corroboram com o conceito de competência definida na Base Nacional Comum Curricular Brasil (2017, p.8) "Competência é definida como a mobilização de conhecimentos (conceitos e procedimentos), habilidades (práticas, cognitivas e socioemocionais), atitudes e valores para resolver demandas complexas da vida cotidiana, do pleno exercício da cidadania e do mundo do trabalho."

Os jogos matemáticos têm a capacidade de ativar nos alunos as habilidades já existentes em cada um deles. Motiva, incentiva e aciona a coordenação motora, mobiliza a capacidade intelectual para o desenvolvimento de estratégias, além de desempenhar papel socializador.

Esta metodologia de aprendizagem reforça que 
“[...] o ensino da Matemática prestará sua contribuição à medida que forem exploradas metodologias que priorizem a criação de estratégias, a comprovação, a justificativa, a argumentação, o espírito crítico, e favoreçam a criatividade, o trabalho coletivo, a iniciativa pessoal e a autonomia advinda do desenvolvimento da confiança na própria capacidade de conhecer e enfrentar desafios" (Brasil, 1997, p.26)

Estudos que reforçam a aplicação dos jogos no ensino e aprendizagem da Matemática, confirmam a interferência positiva dessa ferramenta lúdica. Criação e construção de conceitos é um dos pontos destacados nesses estudos. Segundo Grando (2004), isso é possível desde que haja uma dialética dupla: Matemática e alunos, professor e alunos.

“Analisando a relação entre o jogo e a resolução de problemas, ambos enquanto estratégia de ensino, evidenciamos vantagens no processo de criação e construção de conceitos, quando possível, por meio de uma ação comum estabelecida a partir da discussão Matemática entre os alunos, e entre o professor e os alunos (Grando, 2004, p. 29).”

Sarmento et al (2018) afirma que a utilização do jogo como ferramenta de ensino fornece aos estudantes um ambiente enriquecedor e motivador. Já Smole et al (2007) nos lembra que é preciso mudar o modelo tradicional, trabalhado na educação:

"Em se tratando de aulas de matemática, o uso de jogos implica uma mudança significativa no processo de ensino e aprendizagem, que permite alterar o modelo tradicional de ensino, o qual muitas vezes tem no livro e em exercícios padronizados seu principal recurso didático (Smole et al 2007, p.12)."

Atitude ativa, motivação e diminuição de bloqueios são evidenciados nas palavras de Borin (1996).

"Outro motivo para a introdução de jogo nas aulas de Matemática é a possibilidade de diminuir bloqueios apresentados por muitos de nossos estudantes que temem a Matemática e sentem-se incapacitados para aprendê-la. Dentro da situação de jogo, onde é impossível uma atitude passiva e a motivação é grande, notamos que, ao mesmo tempo em que estes alunos falam Matemática, apresentam também um melhor desempenho e atitudes mais positivas frente a seus processos de aprendizagem (Borin, 1996, p. 9)."

Nessa somatória de benefícios que os jogos proporcionam, Agranionih e Smaniotto (2002), ressaltam a importância que uma atividade lúdica intencionalmente planejada traz. Mais precisamente:

“[...] uma atividade lúdica e educativa, intencionalmente planejada, com objetivos claros, sujeita a regras construídas coletivamente, que oportuniza a interação com os conhecimentos e os conceitos matemáticos, social e culturalmente produzidos, o estabelecimento de relações lógicas e numéricas e a habilidade de construir estratégias para a resolução de problemas (Agranionih, \& Smaniotto, 2002)."

Os jogos matemáticos além de contribuir para o desbloqueio dos educandos, melhorando a motivação pessoal e autoestima, incentiva o pensamento criativo, com raciocínio lógico e grupal. Para Sarmento et al (2018), os jogos em si não só ajudam nas aulas, mas na relação entre as crianças e no respeito pelas regras expostas no meio social. Segundo os Parâmetros Curriculares Nacionais (1997) de Matemática os jogos são desafiadores.

"Finalmente, um aspecto relevante nos jogos é o desafio genuíno que eles provocam no aluno, que gera interesse e prazer. Por isso, é importante que os jogos façam parte da cultura escolar, cabendo ao professor analisar e avaliar a potencialidade educativa dos diferentes jogos e o aspecto curricular que se deseja desenvolver (Brasil, 1997, pp. 4849)."

Trabalhar com jogos matemáticos em sala de aula não consiste apenas em entregar o material aos alunos. É importante a participação ativa do professor na elaboração e desenvolvimento de cada jogo para que o resultado seja o mais favorável possível. Ou seja, é necessário que o professor faça a mediação dos conhecimentos da Matemática com os jogos. 
"Assim, para a aplicação do jogo torna-se necessário que o professor desenvolva um planejamento da aula com o jogo que será utilizado. De início o professor deve saber qual objetivo que ele quer atingir com a aplicação do jogo. Escolher um jogo que seja adequado tanto ao assunto que será trabalhado, quanto aos estudantes a quem será direcionado (Sarmento et al, 2018, p.4)."

Por outro lado, a modelagem matemática também vem sendo uma metodologia diferenciada utilizada em sala de aula, no intuito de auxiliar a atuação e intervenção dos educandos no meio social através de representações que modelam as situações do cotidiano. Além disso, pode promover o interesse dos alunos por meio de situações do dia a dia relacionadas ao conteúdo matemático desenvolvido em sala de aula.

Alguns autores se destacam pela maneira como definem a modelagem matemática. De acordo com Bassanezi (2009),

"Modelagem matemática é um processo dinâmico utilizado para a obtenção e validação de modelos matemáticos. É uma forma de abstração e generalização com finalidade de prevenção de tendências. A modelagem consiste, essencialmente, na arte de transformar situações da realidade em problemas matemáticos cujas soluções devem ser interpretadas na linguagem usual (Bassanezi, 2009, p. 24).”

Ainda, para Bassanezi (2002, p.16), "a Modelagem matemática consiste na arte de transformar problemas da realidade em problemas matemáticos e resolvê-los interpretando suas soluções na linguagem do mundo real”. Sendo assim, podemos perceber que o objetivo da modelagem matemática é propiciar uma descrição matemática de um dado fenômeno do cotidiano. Normalmente, esta descrição é realizada por meio de equações matemáticas e é denominada modelo matemático.

O autor reitera dizendo que a "Modelagem matemática é um processo dinâmico utilizado para a obtenção e validação de modelos matemáticos. É uma forma de abstração e generalização com a finalidade de previsão de tendências" (Bassanezi, 2002, p.24).

Na perspectiva de Burak (1992, p.62) “A modelagem matemática constitui-se em um conjunto de procedimentos cujo objetivo é tentar explicar, matematicamente, os fenômenos presentes no cotidiano do ser humano, ajudando-o a fazer predições e a tomar decisões."

Tais definições sintonizam com o que prevê a Base Nacional Comum Curricular (BNCC) sobre a modelagem matemática, quando afirma que

“[...] no Ensino Fundamental, essa área, por meio da articulação de seus diversos campos - Aritmética, Álgebra, Geometria, Estatística e Probabilidade -, precisa garantir que os alunos relacionem observações empíricas do mundo real a representações (tabelas, figuras e esquemas) e associam essas representações a uma atividade matemática (conceitos e propriedades), fazendo induções e conjecturas (Brasil, 2017, p. 265).”

D’Ambrósio (1986) afirma que a modelagem matemática é uma dinâmica de realidade, ou seja, uma reflexão sobre a realidade que consiste na tentativa de desvendar o comportamento do indivíduo de forma individual, social e cultural. Para ele, o modelo seria um vínculo que pudesse ligar às informações coletadas pelo indivíduo, sua ação sobre a realidade existente. Nesse sentido, criar um modelo está vinculado ao fato de definir as estratégias de ação do próprio indivíduo sobre a realidade.

Sobre a inclusão da modelagem matemática como alternativa de ensino de Matemática, estudiosos como Bassanezi (2002), Biembengut (1999); Biembengut e Hein (2005) têm-se mostrado favoráveis. Suas reflexões apontam que esta metodologia consiste em possibilidades do desenvolvimento de distintas habilidades da consciência da participação sóciocultural da Matemática, bem como sua utilização em diferentes áreas.

Concordamos com Biembengut (1999, p.36), ao afirmar que: “[...] a modelagem matemática no ensino pode ser um caminho para despertar no aluno o interesse por tópicos matemáticos que ainda desconhece ao mesmo tempo em que aprende a arte de modelar, matematicamente." 
Por outro lado, o processo de ensino via modelagem está congruente com as diretrizes propostas nos Parâmetros Curriculares Nacionais no trecho:

"No decorrer dos primeiros ciclos do Ensino Fundamental os alunos devem ser levados a desenvolver a familiarização com a contagem de agrupamentos, de maneira informal e direta, fazendo, por exemplo, uma lista de todos os agrupamentos possíveis para depois contá-los (Brasil, 1997, p. 52).”

Para a aplicabilidade da modelagem matemática no setor educacional, Bassanezi (2002) afirma que é necessário um processo que envolve diversas etapas. Sucintamente, são elas:

1- Experimentação - Consiste na seleção das variáveis. É o momento de interação com o reconhecimento da situação-problema. Nessa etapa prioriza a obtenção dos dados empíricos, que funcionam como agentes na compreensão do problema.

2 - Abstração - fase de formulação do problema, ou situação real, é a matematização da situação-problema.

3 - Resolução - Consiste em transferir o problema real para a linguagem matemática.

4 - Validação - Consiste em aceitar ou recusar o modelo inicial comparando a solução obtida do modelo matemático com os dados reais.

5 - Modificação - Se o resultado da etapa 4 não for aceitável, então modifica-se o modelo original para então reiniciar o processo.

6 - Aplicação - Se a modelagem mostrar eficaz, então esta permite explicar o mundo real.

Para Bassanezi (2009) seguindo estas etapas, o conteúdo matemático vai sendo sistematizado e aplicado. E ainda ressalta que "Com a modelagem o processo de ensino-aprendizagem não mais se dá no sentido único do professor para o aluno, mas como resultado da interação do aluno com seu ambiente natural. (Bassanezi, 2009, p.38).”

A fim de que as atividades sejam realizadas da melhor forma possível, dando origem a um resultado mais produtivo e positivo, em todas as etapas do processo, o professor deve instigar e incentivar os alunos. Sendo assim, durante todo o método da Modelagem, a conduta do professor é essencial, uma vez que ele desempenha o papel de mediador do conhecimento.

Os benefícios da utilização da modelagem matemática em sala de aula se estendem. $O$ uso dessa alternativa de ensino permite trabalhar a interdisciplinaridade, a transversalidade, mostrando ao aluno como a Matemática pode ser útil em sua vida fora do ambiente escolar e como ela interage com as demais áreas do conhecimento.

Um dos aspectos que promove a interdisciplinaridade na modelagem matemática é a escolha do tema, o que permite um diálogo entre as diversas áreas do conhecimento, promovendo um trabalho de equipe entre professores. Segundo Setti \& Vertuan (2021, p.8) "Por isso é natural associar Modelagem Matemática à interdisciplinaridade, isto porque a atividade de Modelagem, na maioria das vezes, é sobre um tema não matemático, de outra área, podendo integrar, inclusive, diversas áreas."

De acordo com os PCN's Brasil (1997), é importante que os temas transversais, tais como, ética, saúde, meio ambiente, orientação sexual, sejam explorados na escola. Por estes temas apresentarem uma característica bem ampla, é possível elaborar um trabalho com a modelagem matemática, levando em conta a realidade dos alunos e auxiliando na sua aprendizagem.

Pensando na interdisciplinaridade e transversalidade associadas à modelagem matemática, Setti e Vertuan (2021, pp.8-9) afirmam que "Em atividades de Modelagem Matemática os conhecimentos acabam sendo utilizados e reinventados, ressignificados à medida que são trabalhados de modo não isolado, mas de modo integrado.” 


\subsection{Alguns exemplos de modelagem matemática e jogos matemáticos como alternativas metodológicas de ensino e aprendizagem}

As situações ligadas ao dia a dia podem se tornar contextos interessantes a serem explorados dentro da sala de aula. Partindo deste fato, o trabalho de Junior (2011), baseado na obra de Beimbengut e Hein (2005) relaciona a Modelagem Matemática com as necessidades do mundo moderno como construir uma casa, estabelecendo padrões de medida e forma triangular que aparece em diversas estruturas, como portões, telhados, pontes, dentre outras.

É possível abordar a modelagem matemática como uma alternativa de ensino que se dá através de uma interação contextualizada do educando com suas realidades, utilizando noções de combinatória. Nessa perspectiva, Brumano (2014) explorou o assunto análise combinatória com o tema "O restaurante self service" sugerido pelos alunos. Seu trabalho foi baseado na obra de Barbosa (2003) onde a partir de levantamento de dados de um restaurante, os alunos puderam identificar problemas de contagem por meio dos princípios aditivo e multiplicativo.

Temáticas como Reciclagem, Decomposição de materiais na natureza e Fast food podem se somatizar às possibilidades de atividades de modelagem que podem ser desenvolvidas. Komar (2017) apresentou algumas alternativas de atividades relacionadas a essas temáticas. Os alunos, após quantificar o lixo reciclável produzido no ambiente de um colégio, trabalharam o peso do lixo coletado, recordando conceitos sobre subtração, razão e proporção, funções ou equações do $1^{\circ}$ grau e vincularam o cálculo de perguntas propostas pelo professor fazendo uso da regra de três simples. Na atividade desenvolvida foi comentado também sobre equações lineares e sistemas lineares.

Para proporcionar uma aprendizagem sólida e significativa sobre equações do primeiro grau, Nazareth (2017), em sua dissertação, explorou o jogo da memória e dominó de equações. Nestes, foi observada a satisfação por parte dos alunos participantes e o resultado positivo aproximou-se da unanimidade.

São várias as opções de jogos matemáticos apresentados no trabalho de Silva (2013). Desde jogos que incentivam noções espaciais, estudos de logaritmos e exponenciais, quadrados perfeitos, equações, parábolas, tempo, movimento, estimativas e reconhecimento de unidades, conteúdos de probabilidade, análise combinatória. Conteúdos relacionados com divisibilidade; múltiplos; números primos estão entre os assuntos abordados através dos jogos. Sumariamente, os exemplos de jogos supracitados são importantes recursos pedagógicos para o ensino de Matemática, reafirmando a influência ativa no ensino efetivo além de propiciar interações sociais que se dá a partir de uma concepção de inclusão.

Engelmann (2014) apresentou uma série de jogos com o objetivo de elaborar estratégias inovadoras que permitissem a assimilação da Matemática pelos alunos. Através desses jogos podemos explorar vários conteúdos matemáticos, tais como: as operações básicas da Matemática, números naturais, inteiros e reais, frações, mínimo múltiplo comum e mínimo divisor comum, potenciação, radiciação, fatorial, logaritmos, equações de $1^{\circ}$ e $2^{\circ}$ graus, coeficientes, soma e produto de raízes, discriminante, entre outros.

A fim de sanar as dúvidas dos alunos com relação ao conteúdo de fração, Silva et al (2020) apresentaram dois jogos matemáticos envolvendo esse conteúdo e concluíram a importância da utilização dos jogos, uma vez que os alunos conseguiram relacionar a aplicação das frações com seu cotidiano. Além disso, por meio da interação dos alunos, os autores perceberam uma maior participação e interesse na realização dos cálculos, favorecendo assim uma aprendizagem mais significativa.

Zanette e Tortola (2019), por sua vez, com o objetivo de introduzir jogos em atividades de modelagem matemática, analisaram a possibilidade de um jogo fomentar atividades de modelagem no Ensino Fundamental. Através de um jogo para dispositivos móveis no qual o jogador tem como meta ampliar sua fazenda e deixá-la cada vez mais produtiva, conhecido como Hay Day, os autores detectaram quais situações-problema com o uso da Matemática poderiam ser inseridas em uma atividade de modelagem matemática. 


\section{Considerações Finais}

O foco deste trabalho foi realizar uma pesquisa bibliográfica quanto às concepções teóricas relacionadas à Modelagem Matemática e aos jogos matemáticos. Além disso, buscou-se salientar como essas metodologias podem ser utilizadas auxiliando o processo de ensino e aprendizagem da Matemática.

De modo geral, percebemos que esses estudos vêm contribuindo de modo positivo no desenvolvimento de novas técnicas de ensino dos conteúdos matemáticos. Essas ações reforçam a prática de metodologias ativas presentes na Base Nacional Comum Curricular, Brasil (2017), que visam fazer com que o estudante se torne o protagonista do seu aprendizado.

Além disso, demonstram a viabilidade de construir diferentes metodologias no ensino da Matemática, sendo possível dar a devida relevância aos trabalhos de educadores e educadoras dos Ensinos Fundamental e Médio.

Em decorrência da leitura e análise dos documentos estudados, percebemos a importância da interação entre a escola e a Matemática a fim de preparar os alunos para a sociedade em que estão inseridos, contribuindo para a formação de cidadãos com responsabilidade, capazes de participar ativamente no mundo permeado pela ciência e tecnologia.

Acreditamos que é possível, de modo gradual e contínuo, agregar os pontos previstos nas políticas públicas orientadoras de currículo e os estudos dos autores mencionados ao ensino ministrado na sala de aula. Nesse sentido, tanto os jogos quanto a Modelagem Matemática, possuem a capacidade de promover nos alunos as observações empíricas do mundo real com a matemática abstrata, proporcionando o encontro entre teoria e prática, conforme os registros presentes nos trabalhos do teórico D’ambrósio (1986) e (2009).

Identificamos que jogos matemáticos bem elaborados são capazes de contribuir positivamente na compreensão dos conteúdos matemáticos. À medida que o professor consegue mediar e explorar a relação do jogo com os conteúdos matemáticos, os alunos constroem seus conhecimentos de forma ativa, atribuindo significado aos conteúdos.

Assim são diversos os benefícios da aplicação dos jogos matemáticos, tais como motivação e curiosidade dos alunos e professores na execução dos jogos, o estímulo do pensamento crítico, a motivação para trabalhar soluções de situações problemas de forma individualizada e grupal, além da possibilidade de pensar em diferentes estratégias de ação de forma divertida.

Percebemos também que o desenvolvimento da metodologia Modelagem Matemática em sala de aula, motiva a participação do aluno na construção de modelos matemáticos a partir dos dados empíricos que representam a situação real e conhecida, aproximando a vivência da resolução de problemas. Além disso, possibilita o pensar em diferentes formas de resolver o problema, bem como a possibilidade de interação do conteúdo matemático com outras disciplinas.

Em ambas as metodologias, é possível perceber o aprimoramento do aluno enquanto cidadão crítico e transformador (agente) da sua realidade. Além disso, enxergamos a participação ativa da matemática no contexto sócio-cultural, possibilitando sua conexão com a realidade vivenciada pelo aluno.

Estabelecendo de forma breve um paralelo entre essas metodologias e o ensino tradicional, é perceptível nas metodologias supracitadas, o interesse pelo estudo da Matemática e a motivação e o entusiasmo por parte dos alunos. Os resultados positivos da inserção dessas metodologias afirmam a relevância da utilização de ferramentas facilitadoras do aprendizado dos conteúdos matemáticos.

Por fim, entendemos que o emprego da Modelagem Matemática e dos Jogos Matemáticos na sala de aula, potencializa a aprendizagem e a ressignificação de conceitos matemáticos. Ao elaborar atividades que vinculam os conteúdos matemáticos à realidade dos alunos, o professor desperta nos estudantes uma maior motivação para o aprendizado. Nesse sentido, nos próximos artigos pretendemos verificar de que forma os professores vêm utilizando as ferramentas metodológicas na sala de aula, acentuando suas dificuldades e limitações, principalmente durante o período de pandemia, no qual foi necessária a reinvenção das técnicas de ensino. 


\section{Referências}

Agranionih, N. T. \& Smaniotto, M. (2002). Jogos e aprendizagem Matemática: uma interação possível. EdiFAPES.

Barbosa, J. C. (2003). Modelagem Matemática na sala de aula. Perspectiva, Erechim (RS), 27 (98), 65-74.

Bassanezi, R. C. (2002). Ensino-aprendizagem com modelagem matemática. Contexto.

Bassanezi, R. C. (2009). Ensino-aprendizagem com modelagem matemática: uma nova estratégia. Contexto.

Biembengut, M. S. (1999). Modelagem matemática \& implicações no ensino e aprendizagem de matemática. FURB.

Biembengut, M. S. \& Hein, N. (2005). Modelagem Matemática no Ensino. Contexto.

Borin, J. (1996). Jogos e resolução de problemas: uma estratégia para as aulas de Matemática. IME-USP.

Brasil (1997). Ministério da Educação e do Desporto e Secretaria de Educação Fundamental. Parâmetros Curriculares Nacionais. Matemática: Ensino de primeira à quarta série. $\mathrm{MEC} / \mathrm{SEF}$.

Brasil (2017). Ministério da Educação. Base Nacional Comum Curricular. MEC/SEF.

Brumano, C. E. P. (2014). A Modelagem Matemática como metodologia para o estudo de análise combinatória (Dissertação de Mestrado em Educação Matemática). Universidade Federal de Juiz de Fora, MG.

Burak, D. (1992). Modelagem Matemática: uma metodologia alternativa para o ensino de matemática na $5^{\mathrm{a}}$ série. (Dissertação de Mestrado em Educação Matemática). Universidade Estadual Paulista Júlio Mesquita Filho, SP.

D'ambrósio, U. (1986). Da Realidade à Ação: Reflexões sobre Educação Matemática. UNICAMP.

D’ambrósio, B. S. (2009). Educação Matemática: da teoria à prática. Papirus.

Dauanny, E. B. (1994). Para além do conhecimento matemático. Uma experiência na quinta série do primeiro grau (Dissertação de Mestrado em Educação Matemática). Universidade Federal de Minas Gerais, MG.

Elgemann, J. (2014). Jogos matemáticos: experiências no PIBID. IFRN.

Freire, P. (1998). Pedagogia da autonomia. Paz e Terra.

Goulart, I. B. (2002). Piaget: Experiências Básicas para Utilização pelo Professor. Vozes.

Grando, R. C. (2004). O jogo e a Matemática no contexto da sala de aula. Paulus.

Junior, C. P dos S. (2011). Modelagem matemática: uma ferramenta importante para aprendizagem do ensino da Matemática no mundo das tecnologias. XIII Conferência Interamericana de Educação Matemática, Universidade Federal de Pernambuco.

Komar, M. F. C. (2017) Modelagem Matemática no processo de ensino e aprendizagem da Matemática no ensino fundamental: ações e interações (Dissertação de Mestrado em Ensino de Ciências Naturais e Matemática). Universidade Estadual do Centro-Oeste, PR.

Libâneo, J. C. (1994). Didática. Cortez.

Libâneo, J. C. (2010). Pedagogia e pedagogos, para quê? Cortez.

Nacarato, A. M. (2013). O professor que ensina matemática: desafios e possibilidades no atual contexto. Espaço Pedagógico, 20 (1), $11-32$.

Nazereth, D. R. (2017). O uso de jogos como estratégia de aprendizagem de equações de primeiro grau para o Ensino Fundamental II, (Dissertação de mestrado em Ciências). Universidade de São Paulo, SP.

Philippi, J. R. A. (2000). Interdisciplinaridade em Ciências Ambientais. Signus Editora.

Santos, T. C. \& Costa, M. A. F. (2015). Um olhar sobre a Educação Ambiental expressa nas Diretrizes Curriculares Nacionais para a Educação Ambiental. Revista Práxis, 7 (13), 143-151.

Sarmento, C. V. S et al. (2018). A importância dos jogos matemáticos para a aprendizagem: aplicação do jogo conhecendo a equação no ensino médio. https://semanaacademica.org.br/system/files/artigos/a_importancia_dos_jogos_matematicos_para_a_aprendizagem_0.pdf

Scoz, B. (1996). Psicopedagogia e realidade escolar: o problema escolar e de aprendizagem. Petrópolis Vozes.

Setti, E. J. K., \& Vertuan, R. E. (2021). Modelagem Matemática no Curso Técnico de Informática Integrado ao Ensino Médio: uma abordagem interdisciplinar. Revista de Ensino de Ciências e Matemática, 12 (2), 1-25.

Silva, D. G. T et al. (2020). O lúdico como recurso didático para o ensino de frações no $6^{\circ}$ ano do Ensino Fundamental. Research, Society and Development, 9 (11), 1-18.

Silva, D. L. (2013). Jogos Matemáticos nas Aulas do Ensino Médio: Um Estudo dos Trabalhos Publicados no ENEM. (Monografia para obtenção do título de licenciatura em Matemática). Instituto Federal de Ciência e Tecnologia de São Paulo. 
Research, Society and Development, v. 11, n. 1, e41411124886, 2022

(CC BY 4.0) | ISSN 2525-3409 | DOI: http://dx.doi.org/10.33448/rsd-v11i1.24886

Smole, K. S. \& Diniz, M. I. \& Cândido, P. (2007). Jogos de matemática de $1^{\circ}$ ao $5^{\circ}$ ano. Artmed.

Unesco (2016). Os desafios do ensino de matemática na educação básica. Edufscar.

Vygotsky, L. S. (2003). A formação social da mente. Martins Fontes.

Zannete, G. H., \& Tortola, E. (2019). Modelagem matemática e jogos: articulações e possibilidades para o Ensino Fundamental. XI Conferência Nacional sobre Modelagem na Educação Matemática. UFMG. 